\title{
Asymmetric Expression of a Novel Homeobox Gene in Vertebrate Sensory Organs
}

\author{
David L. Deitcher, ${ }^{a}$ Donna M. Fekete, ${ }^{b}$ and Constance L. Cepko \\ Department of Genetics, Harvard Medical School, Boston, Massachusetts 02115
}

\begin{abstract}
A novel homeobox gene, SOHo-1, was isolated from embryonic chicken retina. On embryonic day 2 (E2), SOHo-1 is expressed in the retina, posterolateral otic pit, and neural tube anterior to the spinal cord. On E4, SOHo- 1 is expressed at high levels in anterior retina and low levels in posterior retina, suggestive of a role in patterning the anterior-posterior axis. It is also expressed on E4 in the otocyst, the dorsal root ganglia, some cranial ganglia, and the second branchial arch. SOHo-1 expression in the otic pit and otocyst is restricted to regions that will give rise to the nonsensory tissues of the inner ear. SOHO- 1 is not closely related to any identified vertebrate or Drosophila homeobox-containing genes. Since it is expressed in sensory-related structures and does not fit into existing classes of homeobox genes, we propose the name SOHo-1, for sensory organ homeobox-1.

[Key words: homeobox, sensory organs, retina, otocyst, anterior-posterior, development]
\end{abstract}

The highly complex morphogenetic movements, cell fate decisions, and differentiation that occur during CNS development are controlled by an intricate network of gene products, some of which are similar to those identified in invertebrates. For example, in Drosophila, the homeobox genes have been shown to control basic patterning in the developing embryo through conversion of gradients of expression to a segmental pattern (reviewed in Akam, 1987). The homeobox genes eve and $f t z$ have been proposed to be required for correct cell fate decisions in neurons in which they are expressed (Doe et al., 1987, 1988). In the eye, it has been demonstrated that expression of the rough homeobox gene in photoreceptors R2 and R5 is necessary for proper development of the other photoreceptors (Tomlinson et al., 1988). More recently, the homeobox genes orthodenticle and empty spiracles have been shown to be regulated by bicoid in a manner similar to that of the gap genes (i.e., hunchback), suggesting that they specify broad regions in the Drosophila head

\footnotetext{
Received Feb. 19, 1993; revised July 23, 1993; accepted July 29, 1993.

We thank M. Mueckler for advice on cDNA libraries, H. G. Simon for expertise on in situ hybridization, E. Snyder for help in figure preparation. T. Burglin, D. Duboule, and C. Tabin for helpful discussions on homeobox genes, D. Noden for helpful discussions on branchial arches, D. Contanche and B. Hay for expertise and advice on anatomical identification, and N. Sucher, D. Wu, and L. Lillien for critical reading of the manuscript. This work was supported by National Institutes of Health Grants T32 EY07110 (D.L.D.), F32 EY06315 (D.M.F.), and R01 EY08064 (C.L.C.).

Correspondence should be addressed to Connie Cepko, Department of Genetics, Harvard Medical School, 200 Longwood Avenue, Boston, MA 02115.

aPresent address: Department of Molecular and Cellular Physiology, Stanford Medical School, Stanford, CA 94305

'Present address: Department of Biology, Boston College, Chestnut Hill, MA 02167.

Copyright (C) 1994 Society for Neuroscience $0270-6474 / 94 / 140486-13 \$ 05.00 / 0$
}

(Cohen and Jürgens, 1990; Finkelstein and Perrimon, 1990). A growing list of homeobox genes are also known to be expressed in the developing vertebrate brain (Lazzoro et al., 1991; Porteus et al., 1991; Price ct al., 1991, 1992; Simconc ct al., 1992a,b).

Evidence is accumulating to support the notion that some homeobox genes in vertebrates act in analogous manners to those in Drosophila. Recently, it was shown that the Deformed regulatory element, which in the fly directs the transcription of Deformed in posterior portions of the head segment, can, when fused to a transgene, direct the specific expression of this transgene in the hindbrain of a mouse (Awgulewitsch and Jacobs, 1992). Reciprocal experiments have shown that human HoxD-4 can direct the expression of endogenous Deformed in Drosophila (McGinnis et al., 1990) and that the HoxD-4 autoregulatory element can direct head-specific expression in Drosophila (Malicki et al., 1992). Targeted mutations in the homeobox gene Hoxa- $I$ in mice, produced by homologous recombination in embryonic stem (ES) cells, revealed that it was required for the proper formation of the ear, cranial nerves, and hindbrain (Lufkin et al., 1991; Chisaka et al., 1992). Recent experiments demonstrated that misexpression of Hoxd- $I 1$ perturbs the positional information in the limb, resulting in an apparent posterior transformation of the anterior portion of the limb (Morgan et al., 1992). Such experiments indicate that homeobox genes play key roles in patterning of the vertebrate embryo.

Approximately 30 years ago, it was predicted that cells in the retina had acquired positional information by virtue of their locations relative to two orthogonal gradients, anterior-posterior (A-P) and dorsal-ventral (D-V) (Sperry, 1963). Heterotopic transplantation of small groups of retinal cells in Xenopus indicated that they retained their A-P and D-V positional information when moved to different locations (Fraser, 1991). Since homeobox genes have been shown to be involved in patterning in other systems, we reasoned that such genes could be involved in endowing positional information in the retina. Thus, we sought to isolate homeobox-containing genes from the retina and characterize their expression. In this article we describe the isolation of a novel homeobox gene from the embryonic chicken retina, called SOHo- 1 , for sensory organ homeobox-1. In stage 14 chicks [embryonic day 2 (E2)], it is expressed in the retina, otocyst, prosencephalon, mesencephalon, and rhombencephalon. By E4, SOHo- 1 is expressed at high levels in the nasal (anterior) retina and at low levels in the temporal (postcrior) retina, suggesting that it may play a role in A-P patterning in the retina. High levels of expression are also seen in the portions of the otocyst that give rise to non-neural structures and in the developing dorsal root ganglia (DRG) along the entire length of the spinal cord. The second branchial (hyoid) arch also expresses high levels of $\mathrm{SOHO}_{-1}$ on E4. 


\section{Materials and Methods}

cDNA library construction and screening. Five micrograms of poly $\mathrm{A}^{+}$ RNA were used to generate double-stranded oligo-dT-primed cDNA as described (Gubler, 1988) except first-strand buffer contained $2.5 \mathrm{~mm}$ $\mathrm{K}+$. Blunt-ended cDNA was methylated with EcoRI methylase (New England Biolabs), linkcred with EcoRI linkcrs, and digested with EcoRI (New England Biolabs). The cDNA was passed over a G100 column (Pharmacia) and then size selected for cDNAs of $>1$ kilobase $(\mathrm{kb})$ by agarose gel electrophoresis, glass purified (Vogelstein and Gillespie, 1979), cloned into phosphatased $\lambda \mathrm{gt} 1 \mathrm{l}$ arms (Clonetech), and packaged with Gigapack Gold (Stratagene), yiclding a library of $6 \times 10^{6}$ recombinants; $1 \times 10^{\circ}$ plaques were screened with a synthetic 110 -base pair (bp) oligonucleotide (Applied Biosystems) that was end labeled with $\gamma^{-{ }^{32} \mathrm{P}-}$ ATP $(6000 \mathrm{Ci} / \mathrm{mmol}$; New England Nuclear) by T4 polynucleotide kinase (Boehringer Mannheim Biochemicals). The 110-mer sequence was based on a polymerase chain reaction (PCR) probe generated from firststrand cDNA derived from E6 chicken eye. The PCR utilized Taq DNA polymerase (Perkin-Elmer/Cetus) and consisted of $5 \mathrm{~min}$ at $95^{\circ} \mathrm{C}$, and then 35 cycles of $95^{\circ} \mathrm{C}$ for $1 \mathrm{~min}, 50^{\circ} \mathrm{C}$ for $2 \mathrm{~min}$, and $72^{\circ} \mathrm{C}$ for $3 \mathrm{~min}$ under standard buffer conditions. The PCR primers were designed to hybridize to conserved portions of murine homeobox genes. The $5^{\prime}$ primer was $5^{\prime}$ CTGGAGAAGGAATTCCAC $3^{\prime}$ and the $3^{\prime}$ primer was 5 ' C/GCGATTCTGGAACCAGATCTT 3'. The resulting PCR product was subcloned into mpl 8 and several clones were sequenced. The sequence of one of the clones (CK3) that contained a homeobox was used to synthesize an oligonucleotide with the same sequence for screening the cDNA library. Plaques were screened at a density of 150,000 per $24 \mathrm{~cm} \times 24 \mathrm{~cm}$ plate, transferred to Hybond-N (Amersham), autoclaved 2 min dry cycle in an autoclave, UV cross-linked, and hybridized overnight in $6 \times$ saline-sodium citrate (SSC) $0.05 \%$ sodium pyrophosphate, $5 \times$ Denhardt's, $100 \mu \mathrm{g} / \mathrm{ml}$ salmon sperm DNA, and $0.5 \%$ SDS at $62^{\circ} \mathrm{C}$ with $2 \times 10^{\circ} \mathrm{cpm} / \mathrm{ml}$. Filters were washed at $37^{\circ} \mathrm{C}$ in $4 \times \mathrm{SSC}, 0.1 \%$ SDS for $1 \mathrm{hr}$, and then at $62^{\circ} \mathrm{C}$ in $2 \times \mathrm{SSC}, 0.1 \% \mathrm{SDS}$ for $30 \mathrm{~min}$. Filters were exposed on Kodak $X \wedge \mathrm{R}$ film with an intensifying screen at $-80^{\circ} \mathrm{C}$ for $2 \mathrm{~d}$. After three rounds of plaque purification, two $\lambda$ clones, $5 \mathrm{~A}-3$ and 5B-3, were subcloned into the EcoRI site of Bluescript $\mathrm{KS}^{+}$(Stratagene).

Chick embryos. Fertilized White Leghorn eggs (SPAFAS, Inc., Norwich, $(\mathrm{T})$ were incubated at $38^{\circ} \mathrm{C}$ for indicated times or until the indicated stages as defined by Hamburger and Hamilton (1951).

$R N A$ isolation. RNA was prepared from embryonic tissues that were frozen in liquid $\mathrm{N}_{2}$ and ground in a mortar and pestle, homogenized in guanidinium thiocyanate, and prepared by the $\mathrm{CsCl}$ cushion method (Chirgwin et al., 1979) or the acid-guanidinium-phenol-chloroform method (Chomczynski and Sacchi, 1987). This RNA was either used as total RNA or was polyA' selected twice with oligo-dT cellulose (Collaborative Research) as described by Kingston (1989).

Northern blots. An Ncol/Xhol fragment of SOHO-I (containing the entire open reading frame) was gel purified and labeled by random priming with $\alpha{ }^{32} \mathrm{P}-\mathrm{dCTP}(50 \mu \mathrm{Ci})$ using the Amersham kit. This probe did not cross-hybridize to any other homeobox genes in Southern blots and similar results in Northerns were obtained with probes containing very little homeobox sequence (data not shown). RNA was electrophoresed on a denaturing formaldehyde agarose gel and transferred in $20 \times$ SSC to Hybond-N membrane (Amersham) by capillary action. Hybridization conditions are as described (Joyner et al., 1985) except hybridization temperature was $55^{\circ} \mathrm{C}$. Blots were washed for $15 \mathrm{~min}$ at $25^{\circ} \mathrm{C}$ in $2 \times \mathrm{SSC}, 0.1 \% \mathrm{SDS}$, and then at $65^{\circ} \mathrm{C}$ for $2 \mathrm{hr}$ in $0.1 \times \mathrm{SSC}, 0.1 \%$ SDS. The blots were exposed to Kodak XRP film at $-80^{\circ} \mathrm{C}$ for $2 \mathrm{~d}$ with an intensifying screen. The Northern blot shown in Figure $2 B$ (with $S O H O-1$ probe) was exposed for $5 \mathrm{~d}$ with an intensifying screen.

DNA sequencing. $5 \mathrm{~A}-3$ was sequenced on both strands in its entirety with specific sequencing primers along its length with the Pharmacia T7 Sequencing Kit or the U.S. Biochemical Sequencing Kit. 5B-3 was sequenced (on one strand) and it differed from 5A-3 only at its $3^{\prime}$ end, in utilizing a different polyA site, and at its $5^{\prime}$ end, in terminating four nucleotides short of its presumed initiation ATG. Homology between the 110 bp oligonucleotide probe (used to screen the cDNA library) and clones $5 \mathrm{~A}-3$ and $5 \mathrm{~B}-3$ only consisted of a $20 \mathrm{bp}$ region of homology from the $3^{\prime}$ of the probe. A different homeobox gene than the one encoded by the PCR probe was thus isolated from the cDNA library. Compressions were resolved by subcloning portions of $5 \mathrm{~A}-3$ into $\mathrm{mp} 18$ or mp 19 and employing deazaguanosine or inosine nucleotides (Pharmacia). Sequences were aligned using the GCG Wisconsin package.

Radioactive in situ hybridization. In situ hybridization was performed essentially as described (Zeller and Rogers, 1991) using "S-labeled RNA probes. Slides were pretreated with $2 \%$ aminoalkylsilane in dry acetone (Rentrop et al., 1986) and then 4\% paraformaldehyde to retain sections during subsequent steps. Six-micrometer paraffin parasagittal sections were hybridized with antisense RNA probe synthesized from EcoRI/ Pvull fragment ( -35 to 423) of $\mathrm{SOHo}-1$ after base hydrolysis. Parafilm (American National Can) was used in place of coverslips during hybridization, and $100 \mu \mathrm{g} / \mathrm{ml}$ of cold $S$-labeled RNA synthesized from a Bluescript KS + Pvull fragment (532-977) was included in the hybridization to block nonspecific hybridization. After washing, slides were dipped in 1:1 Kodak NBT-2 emulsion: water mixture and exposed for $10 \mathrm{~d}$ at $4^{\circ} \mathrm{C}$. Slides were counterstained with hematoxylin and eosin and mounted with Dpx (Fluka). Sense probe from the same EcoRI/Pvull fragment was used to control for nonspecific hybridization.

Whole-mount in situ hybridization. A modification of the in situ whole-mount procedure of Conlan and Rossant (1992) was used. Unless stated, all PBT (PBS $+0.1 \%$ Tween 20) wash steps were done three times for 5 min each at room temperature. Stage 12-14 chick embryos were dissected, fixed in $4 \%$ paraformaldehyde for $1 \mathrm{hr}$ at $4^{\circ} \mathrm{C}$, washed in PBT, and dehydrated through $25 \%, 50 \%, 75 \%$ (methanol: PBT), then $100 \%$ methanol. Embryos were rehydrated through a reverse methanol: PBT series, washed in PBT, treated with $6 \% \mathrm{H}_{2} \mathrm{O}_{2}$ in PBT for $1 \mathrm{hr}$, and then rinsed in PBT. Embryos were treated with $10 \mu \mathrm{g} / \mathrm{ml}$ proteinase $\mathrm{K}$ in PBT for $15 \mathrm{~min}$, rinsed in PBT $+2 \mathrm{mg} / \mathrm{ml}$ glycine, rinsed in PBT, fixed in $0.2 \%$ glutaraldehyde $/ 4 \%$ paraformaldehyde in PBT for 20 min, rinsed in PBT, treated with $0.1 \%$ sodium borohydride in PBT (mixed immediately before use), rinsed in PBT, treated with $0.25 \%$ acetic anhydride in $0.1 \mathrm{M}$ triethanolamine- $\mathrm{HCl}, \mathrm{pH} 8.0$, for $10 \mathrm{~min}$, rinsed in PBT, and then prehybridized for $1 \mathrm{hr}$ in $50 \%$ formamide, $5 \times \mathrm{SSC}, \mathrm{pH}$ 4.5 (pH adjusted with citric acid), $50 \mu \mathrm{g} / \mathrm{ml}$ yeast RNA, $1 \% \mathrm{SDS}$, and $50 \mu \mathrm{g} / \mathrm{ml}$ heparin at $70^{\circ} \mathrm{C}$. The digoxigenin-laheled RNA probe was added to a concentration of $1 \mu \mathrm{g} / \mathrm{ml}$, and then hybridization proceeded overnight at $70^{\circ} \mathrm{C}$. Embryos were washed in solution $1(50 \%$ formamide, $5 \times \mathrm{SSC}, \mathrm{pH} 4.5,1 \% \mathrm{SDS}$ ) for $30 \mathrm{~min}$ at $70^{\circ} \mathrm{C}$, and then washed with a $1: 1$ mixture of solution 1 and solution $2(0.5 \mathrm{~m} \mathrm{NaCl}, 10 \mathrm{~mm}$ Tris$\mathrm{Cl}, \mathrm{pH} 7.5,0.1 \%$ Tween 20 ), then three times with solution 2 for $5 \mathrm{~min}$ each. The embryos were then treated twice with $100 \mu \mathrm{g} / \mathrm{ml}$ RNase (in solution 2) for $30 \mathrm{~min}$ at $37^{\circ} \mathrm{C}$ and washed with solution 2 and solution $3(50 \%$ formamide, $2 \times \mathrm{SSC}, \mathrm{pH} 4.5)$, each for $30 \mathrm{~min}$ at $65^{\circ} \mathrm{C}$. They were then washed three times with TBST $(0.14$ м NaCl, 3 mm KCl, 2.5 mm Tris-Cl, pH 7.5, and 0.1\% Tween 20). Embryos were preblocked with $10 \%$ sheep serum in TBST for $1 \mathrm{hr}$ then incubated with antidigoxigenin antibody $(\mathrm{Ab})$ (precoupled to alkaline phosphatase; Bochringer Mannheim Biochemicals) at a dilution of 1:2500 in TBST and $1 \%$ sheep serum. Anti-digoxigenin antidbody $(\mathrm{Ab})$ was preadsorbed on acetone powder made from stage 12-15 chick embryos. Embryos were then washed three times in TBST for $5 \mathrm{~min}$, five times in TBST for 1 hr each, and then three times in freshly prepared NTMT $(100 \mathrm{mM} \mathrm{NaCl}$, $100 \mathrm{~mm}$ Tris-Cl, pH 9.5, $50 \mathrm{~mm} \mathrm{MgCl}_{2}, 0.1 \%$ Tween 20 , and $2 \mathrm{~mm}$ levamisole) for $10 \mathrm{~min}$ each. The embryos were then incubated in NTMT with $34 \mu \mathrm{g} / \mathrm{ml}$ nitroblue tetrazolium and $17 \mu \mathrm{g} / \mathrm{ml}$ 5-bromo-4-chloro3-indolyl phosphate (Boehringer Mannheim Biochemicals) and developed until color was clearly visible. Embryos were washed in PBT and then $100 \mathrm{~mm}$ Tris-Cl, pH 8.0 and $10 \mathrm{~mm}$ EDTA. Embryos were photographed immediately or the next day to avoid increasing background.

RNA probes. An EcoRI-PvuII fragment of $\mathrm{SOHO}_{-1}$ ( -35 to 423) was subcloned into the EcoRI-Smal site of Bluescript KS (Stratagene). The resulting plasmid was digested with HindIII or XbaI, gel purified, and isolated with glass powder/NaI (Vogelstein and Gillespie, 1979). HindIIIdigested plasmid was used for generation of antisense probes, and XbaI plasmids were used for the production of sense probes. ${ }^{35}$ S-labeled RNA probes were prepared as described (Zeller and Rogers, 1991) and hydrolyzed to approximately 150 nucleotides in length. Digoxigenin-labeled RNA probes were synthesized from the same plasmids with the inclusion of $0.65 \mathrm{mM}$ UTP $/ 0.35 \mathrm{~mm}$ digoxigenin-labeled UTP (Boehringer Mannheim Biochemicals) along with $1 \mathrm{~mm} \mathrm{ATP,} \mathrm{CTP,} \mathrm{and} \mathrm{GTP.}$ Synthesis proceeded for $2 \mathrm{hr}$ at $40^{\circ} \mathrm{C}$. The reaction was then digested with DNase I (RNase free) (Boehringer Mannheim Biochemicals) for $15 \mathrm{~min}$ at $37^{\circ} \mathrm{C}$, ethanol precipitated, rinsed in $70 \%$ ethanol, and resuspended at a concentration of approximately $0.1 \mu \mathrm{g} / \mathrm{ml}$. An aliquot of the RNA product, prior to the DNase I digestion, was run on an agarose gel to estimate amount of RNA and efficiency of transcription.

Three-dimensional reconstruction of in situ hybridization sections. Camera lucida drawings of the in situ hybridized sections were prepared from dark-field images through a $10 \times$ objective on a Zeiss Axiophot 
$-35$

TCCGCCGCCACTCCTGCGGT TAGGCTCAGCGCGCC

1 ATG GTG CAG CTC GGG GGA GGC CGC GGA GCC CCA CCG CCT CTC CTG GCC CCA CCG TCG GCC 1 Met val gln leu gly gly gly arg gly ala pro pro pro leu leu ala pro pro ser ala

61 TTC AGC ATC GAC AGC ATC CTG CAG CCC GGT CCC CGC TGC CAG GCC CGG GAG CAG GGG AGG 21 phe ser ile asp ser ile leu gln pro gly pro arg cys gin ala arg glu gin gly arg

121 GCC CGC IGC GCG CIG CCG GAG GAC GAG GAG GAG GAG GAG GAG GAA GAA GAG GGG CCT GCG 41 ala arg cys ala leu pro glu asp glu glu glu glu glu glu glu glu glu gly pro ala

181 GAG GAA CAC CCC ACT AAA GGC TCC ACC GAC TCG GGC AGC GAG AGG CTG CTG GCG GAA GGG 61 glu glu his pro thr lys gly ser thr asp ser gly ser glu arg leu leu ala glu gly

241 CCG CGC CGC GCG GAT GCC GAG GCC GAA GGC GCG GTT TCA CCG CTC ICC ACG GAG AGG ITC 81 pro arg arg ala asp ala glu ala glu gly ala val ser pro leu ser thr glu arg phe

301 CGC GGA TGC CGA CAG CCG TCG CTG CGG GAT ACC GGG GGC IGC GGT AGA GAG AGC GGC AGG 101 arg gly cys arg gln pro ser leu arg asp thr gly gly cys gly arg glu ser gly arg

361 TGT TCA GCG GCG GGA GGC AAG AAG AAG ACG CGG ACC ATC TTC TCC AAG AGC CAG GTC ITC

121 cys ser ala ala gly gly lys lys lys thr arg thr ile phe ser lys ser gln val ohe

421 CAG CTG GAG TCC ACC TTC GAC GTG AAG CGC TAC CTG AGC AGC GCC GAG CGG GCC GGT CTG

141 gln leu glu ser thr phe asp val lys arg tyr leu ser ser ala glu arg ala gly leu

481 GCC GCC GCG CTG CAC CTC ACC GAG ACG CAG GTG AAG ATC TGG ITC CAG AAC CGC CGC AAC

161 ala ala ala leu his leu thr glu thr gln val lys ile tre ohe gln asn argarg asn

541 AAG CTC AAG AGA CAG CTG TCG GCT GAA CCC GAG GGT CCG GGC CAA GCG GAA CCC CCA GGG

181 IYs leu lys argaln leuser ala glu pro glu gly pro gly gln ala glu pro pro giy

601 GAG CCT CCT CCG CCT CCC GCC GCC TCT ITC TCC TTC CCG TCC CTA TAC AAG GAC AGC GCC 201 glu pro pro pro pro pro ala ala ser phe ser phe pro ser leu tyr lys asp ser ala

Figure $1 . \quad$ Nucleotide and deduced amino acid (aa) sequence of the $S O H O-I$ gene and comparison to homeoboxes from $T g H b o x 5$ and ceh-9. A, The sequence of $S O H O-1$. Both the first nucleotide and the initiation methionine are designated position 1. Upstream inframe translational stop codon at -15 is indicated in italics. The acidic-rich region is underlined (aa 47-57) and the homeodomain is both underlined and boldface (aa 127-186). The four putative polyA sites (AATAAA) are underlined at the $3^{\prime}$ end. $B$, Alignment of $S O H o-1$ homeodomain with those from $T g H b a x 5$ of sea urchin and ceh-9 of $C$. elegans. Amino acids that are conserved between $\mathrm{SOHO}-\mathrm{I}$ and $\mathrm{TgHbOX} 5$ and $c e h-9$ are indicated by the reverse boxed regions. The single-letter code for amino acids is used.
661 CTG TTC AGC CGC TGC CTG CTG CCA CTC CCC TIT CCT CTG TTC TAC CCG GGC AGC GCC ATC 221 leu phe ser arg cys leu leu pro leu pro phe pro leu phe tyr pro gly ser ala ile

721 CCC TAC CTC TGC CTT CCC GGT CCG GTC AAG CAC TTC AGC CTG CTG GAC GGG GAC GTA TAG 241 pro tyr leu cys leu pro gly pro val lys his phe.ser leu leu asp gly asp val *

CGTCTCACCTCGGCCCCCGCCCTGTCTCTTGCAGGGGGCGATGGTCCCTGTGGCACAGCCGTACCACCATCAGCTTTC GCCCCGACACGCGGCAGCCGCTCCCAGCCCCGGGGTCCCCCACACGCTGCCGTGTGCCGTCGTGTCAGAGGAGCTTCAA CGAGCGCTGCACTCTGCTCGAGACGGAGAAGAACGGAGCTGCCAAAGAAACCGGGATGCGCTGTGTCTCCTTTCCCTCC ACAGCCTTTCCGTGGCCGCAGTTTAGGAAAGATGATATCTGCCTCAGTCCACGGGAATGGTGCCATCGCGGCTGCCCCC GCACCGTACCGCCACCCGAGAGCGTTGGGTACAGCCCCATCCACTCCGTACGCTCCTCTATCTCACATTCTCCGCCTTT AGTACACCTTCAATTAACGCTICCCCATCTCTGACACTATCAAAATGCAGACACCTCTCTAAATCTCTGTAGCTTCTCT GAATITTGAATTITCGAACCAAACAAGTCCTCTGTCACACITTGIGCTAACCGGTTCCCAAATCAGGGCCCGTCTGATG TITGGCGCACAAGTTACTCATGCTCCTTACGCTAACCCCGCCCCCGGTTGCTCAGGGGATTATTTTATCTGCTGCCCTA CTGTAACGAAGTGCTTTCTTTIGTTTTTTGTTTTAATCCCCCTTAAATCTCCAACCACAITTGICTICTIITGGITTCC GAGTTCACACGCTTIATATIACAAATTGGGAAATAAAACTTTTCTATCAGAAACCCGAGCTGCATGCCTGTTCCGTACA GCCGCTCCAGGGCAGTGTCCAAAGAAAGACGTTTCCTAGAGTGCATCGACGGGTGTTTGTTITAAAAAAIAAAGGTTGAA CGTGCAATCGTGGTGTGGCGAAATTCAGAAGTGCGTGCTAAAATGGGAGACTTGTTGAGTTTTCCGGAGGGAAAAAAAA

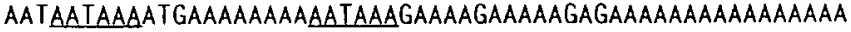

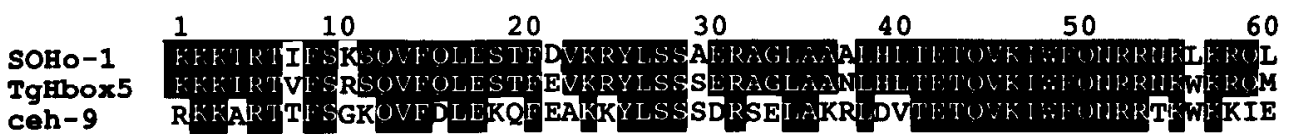

microscope. Grain density considerably above background was subjectively judged to be positive for expression. Semiserial sections were entered into a Sun $386 \mathrm{i}$ workstation with a digitizing tablet. Sections were reconstructed with the Computer Aided Reconstruction Package (CARP; Biographics, Inc., Dallas, TX). Threc-dimensionally reconstructed otocysts were displayed on a high-resolution color monitor and then photographed.

\section{Results}

\section{Isolation of a novel chicken homeobox gene}

We isolated and identified a novel homeobox gene from an E8 chicken cyc cDNA library with a PCR-generated probe. The predicted protein is composed of 259 amino acids, including a homeodomain from amino acid 127 to 186 (Fig. $1 A$ ). The proposed initiation methionine (labeled position 1) was chosen as such since it conforms to the Kozak consensus sequence (Kozak,
1986) and has an in-frame stop codon located 15 nucleotides upstream. Somewhat unusual in this protein sequence is the position of 11 continuous acidic amino acids (47-57) relative to the homeodomain; typically such acidic stretches are found on the carboxyl side of the homeodomain instead of the amino side (Falzon et al., 1987; Kessel et al., 1987; Simeone et al., 1987; Wright et al., 1987).

Homology to other homeobox containing genes, TgHbox 5 and ceh-9

The homeobox in the isolated cDNA does not appear to be a member of the four identified vertebrate Hox clusters since it is not a paralog or homolog of any identified vertebrate Hoxclass homeobox gene and it is not very related to any Drosophila Antennapedia-class homeobox genes, which define Hox-class 
A
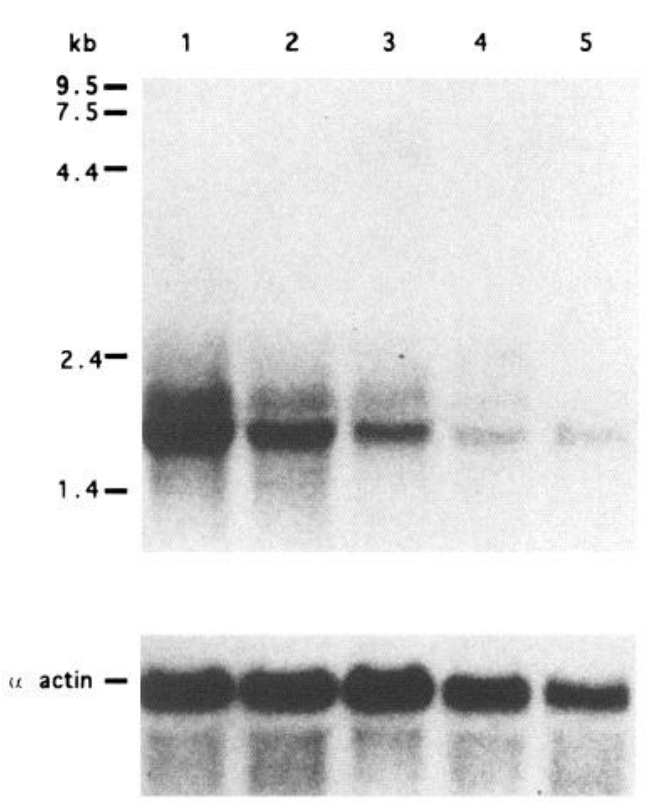

B
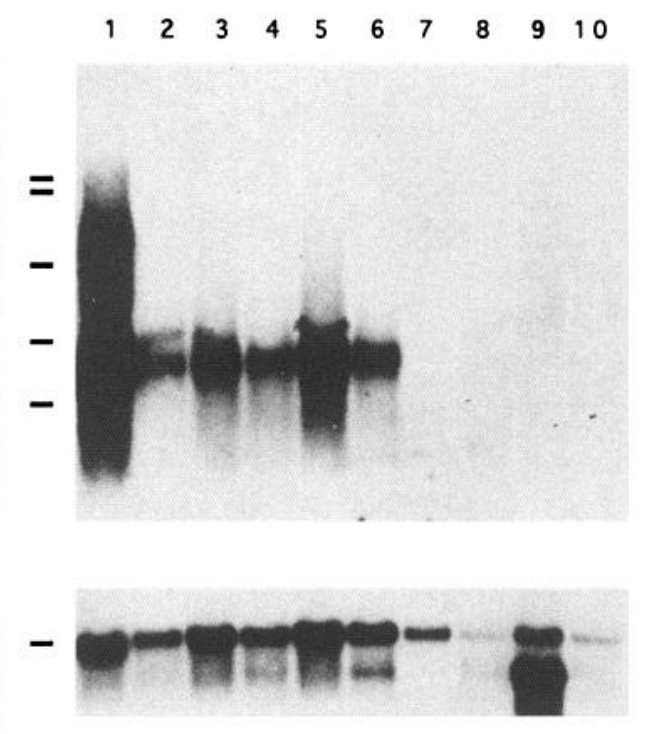

C

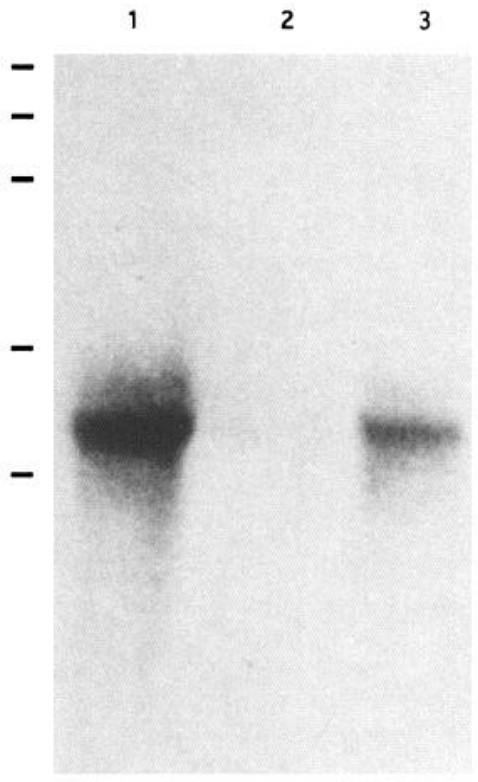

Figure 2. Expression of $\mathrm{SOHo}-\mathrm{I}$ in the embryonic chicken eye and in various embryonic tissues by Northern blot analysis. A, Expression in the eye. Each lane contained $10 \mu \mathrm{g}$ of total RNA from chicken eye at the indicated embryonic times. Size markers (Bethesda Research Labs) are shown to the left in kb. Lane 1, embryonic day 3.5-4 (E3.5-E4); lane 2, E6; lane 3, E8; lane 4, E9.5; lane 5, E13. Below, blot was reprobed with an EcoRI fragment of the human $\alpha$-actin gene to control for amount and integrity of RNA. B. Expression of SOHo-l in embryonic tissues. Each lane contains $5 \mu \mathrm{g}$ of polyA + RNA from indicated embryonic tissues. In order to see expression in embryonic tissues other than the eye, the eyes were not included in any of the samples except lane 1. Lane 1, E6 eye; lane 2, E4 whole embryo; lane 3, E4.5 head; lane 4, E4.5 torso; lane 5, E8 head; lane 6. E8 torso; lane 7, E20 brain; lane 8, E20 heart; lane 9, E20 intestine; lane 10, E20 liver. Below, blot was reprobed with an EcoRI fragment of the human $\alpha$-actin gene to control for amount and integrity of RNA. $\mathrm{C}$, Expression of $S O H o-1$ in developing sensory organs. Each lane contains $5 \mu \mathrm{g}$ of total RNA from the indicated tissues. Lane 1, E6 eye; lane 2, E7 DRG; lane 3, E5 otocyst. Amount and integrity of RNA were controlled for by staining duplicate lanes with ethidium bromide.

homeobox genes in vertebrates. Moreover, this homeobox gene is not closely related to any other homeobox genes from Drosophila characterized to date. Since it is expressed in the retina, the otocyst, and DRG, which are all sensory organs or sensoryrelated structures (see below), and does not clearly fit into existing homeobox classes, we propose the name $\mathrm{SOHo}-1$, for sensory organ homeobox-1. The homeodomain of SOHo-1, however, does have striking homology to the homeodomain of the sea urchin gene $T g H b o x 5$ (Wang et al., 1990); 53 of $60(88 \%)$ amino acids are identical. SOHo- $\mathrm{I}$ and $\mathrm{TgHbox} 5$ also share the unusual positioning of the acidic region relative to the homeobox. The homeodomains of $\mathrm{SOHo}-1$ and ceh-9 (Hawkins and McGhee, 1990) from Caenorhabditis elegans are also similar, with $60 \%$ identity (see Fig. $1 \mathrm{~B}$ ). From amino acid homology, it would appear that these three genes are members of a new family of homeobox genes. We suggest that this new family be named the NEC class, for nematode echinoderm chicken - the organisms from which they were isolated. The significant homology between $\mathrm{SOHo}-1$, ceh-9, and $\mathrm{TgHbox} 5$ in such evolutionarily diverse creatures makes it likely that other members of the proposed NEC family will be found in many other groups of animals including mammals and insects. Whether $\mathrm{SOHo}-\mathrm{I}$ and TgHbox 5 represent true homologs or different members of the same family will become clearer as more related genes are identified.

\section{SOHo-1 is expressed during neurogenesis}

In order to characterize the expression of $\mathrm{SOHo}$ - 1 during chicken eye development, Northern analysis was performed on total
RNA from whole embryonic eyes. At E3.5-E4, strongly hybridizing bands of 1.8 and $2.0 \mathrm{~kb}$ were observed (Fig. $2 A$, lane 1). A steady decline in expression was evident in RNA from E6 and E8 eyes (Fig. 2A, lanes 2, 3), which then reached a lower steady state at E9.5 and E13 (Fig. $2 \mathrm{~A}$, lanes 4,5 ). $\mathrm{SOHo}-1$ is also expressed in adult chicken retina (data not shown). Limited material prevented determination of the onset of $\mathrm{SOHo}-1 \mathrm{ex}-$ pression by Northern analysis prior to E4 in the eye. From partial sequencing of another clone, it appears that the presence of two transcripts is due to utilization of different polyA sites; four such sites were found in the $3^{\prime}$ untranslated region (Fig. $1 A)$. Northern blots probed with $3^{\prime}$ untranslated sequence specific to the larger cDNA clone hybridized to the $2.0 \mathrm{~kb}$ but not to the $1.8 \mathrm{~kb}$ transcript, further supporting the notion that the transcripts differ in size due to $3^{\prime}$ untranslated sequences resulting from differential use of polyA sites (data not shown).

Five micrograms of polyA ${ }^{+}$RNA were prepared at various time points and from different portions of embryos for Northern analysis to see if any other tissues of the embryo contained the SOHo- 1 transcript. RNA from E6 embryonic eyes was run for comparison purposes (Fig. $2 B$, lane 1); although overexposed in Figure $2 B$ and thus difficult to discern, the 1.8 and $2.0 \mathrm{~kb}$ transcripts were observed with shorter exposure times. E4 embryos with the eyes removed had low but detectable levels (Fig. $2 B$, lane 2). On E4.5-E5, expression was observed in both the head and torso (see Fig. $2 B$, lanes 3,4 ), and on E8 head minus eye showed moderate levels of expression while much lower levels were detectable in the torso fraction (Fig. $2 B$, lanes 5,6 ). No expression was detected from brain, liver, heart, and intes- 
Figure 3. Expression pattern of SOHo- 1 in stage 14.5 (approximately E2) chick embryo: Whole-mount in situ hybridization of stage 14.5 chick hybridized with antisense $(A)$ and sense (B) probes of SOHo-1 (lateral views). Dark purple regions indicate areas of specific hybridization with the antisense probe. Note intense signal in the optic cup $(o c)$ from which the retina will form and the semicircular ring on the side of the embryo, which is the lateral posterior portion of the otic pit $(o p)$, the inner ear anlage. Signal is also seen in the brain anlage in the prosencephalon, mesencephalon, and the rhombencephalon. Magnification, $27 \times$.
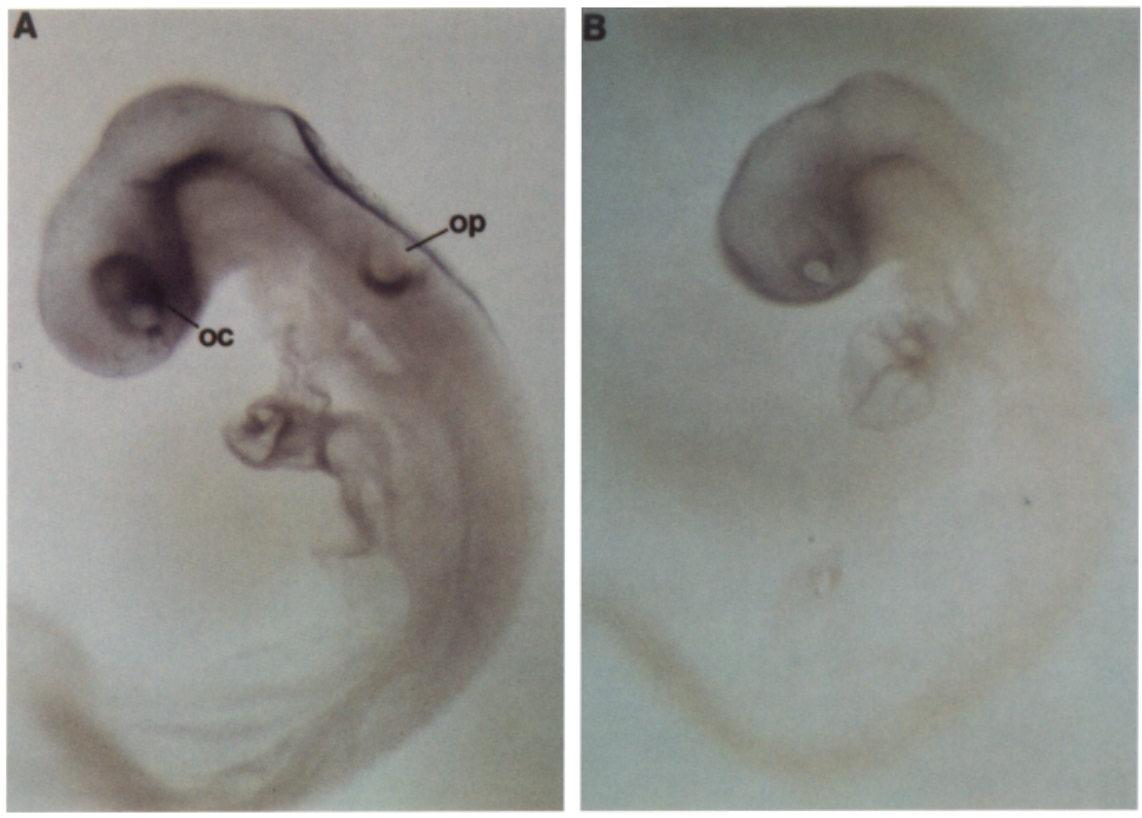

tine from E20 embryos (Fig. 2B, lanes 7-10). In all samples that tested positive for the $\mathrm{SOHo}-\mathrm{I}$ transcript, the predominant transcripts were 1.8 and $2.0 \mathrm{~kb}$, the same molecular weights as the transcripts seen in the eye.

Northern analysis was also performed using $5 \mu \mathrm{g}$ of total RNA from eye, DRG, and otocyst to see if $\mathrm{SOHo}-1$ was expressed in sensory structures. RNA from E6 eye had the highest level of expression (Fig. $2 C$, lane 1), but strong expression was seen in the E5 otocyst as well (Fig. $2 C$, lane 3 ). Faint but detectable levels of $\mathrm{SOHo}-1$ transcript were seen in E7 DRG RNA (Fig. $2 C$, lane 2). In all three samples, transcripts of 1.8 and $2.0 \mathrm{~kb}$ were observed.

\section{SOHo-1 spatial expression in early development}

Whole-mount in situ hybridization was performed to determine whether $\mathrm{SOHo}-\mathrm{l}$ was expressed in early stages of development. Digoxigenin-labeled antisense and sense RNA probes were prepared and hybridized to a number of chick embryos between stages 12 and 14.5 (Hamburger and Hamilton, 1951). In Figure 3 , a typical stage 14.5 embryo is shown after staining for alkaline phosphatase, the tag used to detect the presence of the SOHo-I transcript. Prominent staining was observed in the optic cup (Fig. 3A, labeled oc), both in the inner layer of neuroepithelium which gives rise to the retina and in the outer layer of the optic cup which gives rise to pigmented epithelium. Intense, asymmetrically distributed staining was also observed in the otic pit of stage 14.5 embryo (Fig. $3 A$, labeled op). The most intense staining in the otic pit was in the region most distant from the hindbrain. Strong staining was also present in the neural tube, starting at the most anterior portion of the telencephalon and extending caudally to the posterior end of the rhombencephalon (Fig. 3A). Expression of $\mathrm{SOHo}-1$ was seen in the optic vesicle of a stage 12 chick (data not shown). The whole-mount view of the optic cup did not reproducibly reveal asymmetric expression of $S O H O-1$ in the stage 14.5 retina. The purple precipitate that resulted from the whole-mount in situ procedure was difficult to detect after sectioning, so it could not be determined whether SOHo- 1 was expressed asymmetrically at stage 14.5. Embryos probed with control sense RNA varied from almost no background to a faint bluish background in the head, but the level of blue was always much less intense than the signal observed in antisense embryos (Fig. $3 B$ ). While the whole-mount method was very useful for staining stage 12-14.5 embryos, its usefulness for older embryos was limited as control sense probes revealed that nonspecific background increased dramatically. In order to localize $\mathrm{SOHO}-\mathrm{I}$ transcripts in older embryos, ${ }^{35} \mathrm{~S}$-labeled RNA probes were used on paraffin sections of different staged embryos.

\section{SOHo-1 expression in retina}

Radioactive in situ hybridization was performed on sections to localize the expression of $\mathrm{SOHo}-1$ in the retina. In the stage 23 (E4) chick, the highest domain of $\mathrm{SOHo}-1$ expression was almost entirely in the nasal retina with a minor portion extending across the ventral furrow into the extreme temporal-ventral retina. Except for this small patch of temporal-ventral expression, $\mathrm{SOHo}-1$ was expressed at markedly lower levels on the temporal side. This pattern of hybridization was evident in all the parasagittal sections along the medial-lateral axis (Fig. $4 B, D, F, H)$. Reproducible hybridization was also seen over the developing lens (Fig. $4 F, H$ ). The expression of $\mathrm{SOHo}-1$ extended from the retina into the optic stalk, the neuroepithelialderived structure that later supports the formation of the optic nerve (Fig. $5 D$ and $F$ ) and which possesses some activity in directing the paths of retinal axons (Harris, 1989). In postnatal animals, $\mathrm{SOHo}-\mathrm{I}$ is expressed in all three layers of the mature retina - the outer nuclear, inner nuclear, and ganglion cell layers (Fig. 5B).

\section{SOHo-1 expression in the otocyst}

The vertebrate inner ear develops from an epithelial thickening, called the otic placode, on the surface of the head adjacent to the hindbrain. The otic placode invaginates to form the otic pit, which subsequently pinches off to form the otic vesicle (or otocyst). Ultimately the otic pit gives rise to all of the membranous components of the inner ear, including the sensory organs for 

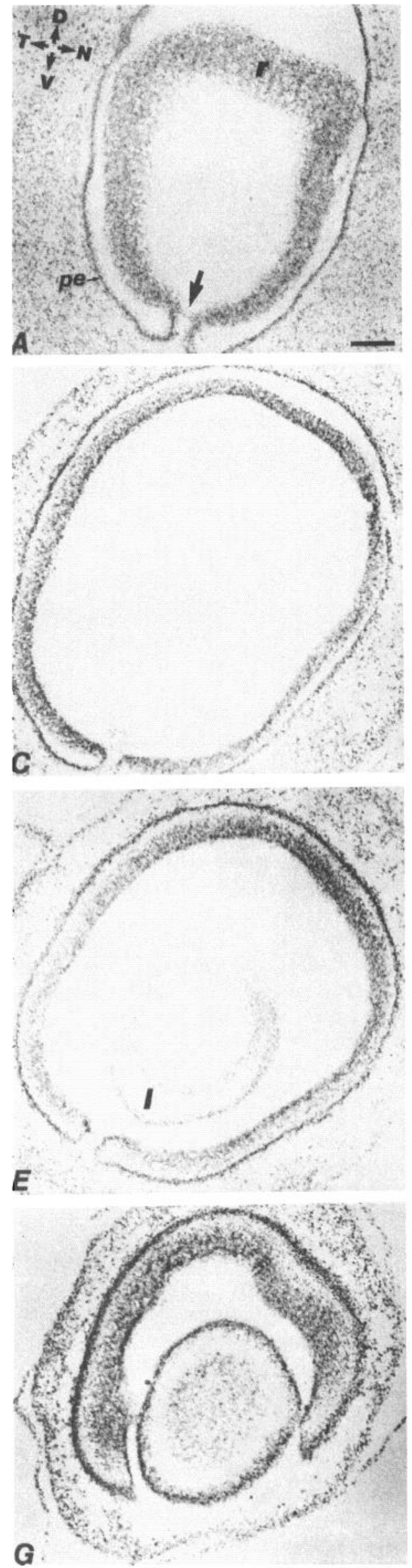
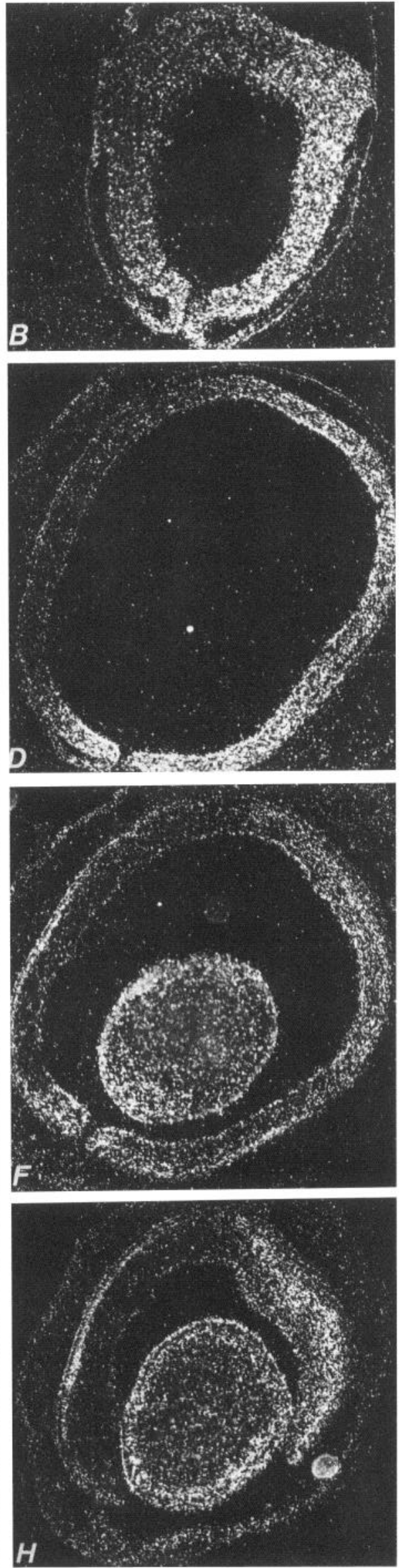

Figure 4. Expression pattern of SOHo- $\mathrm{I}$ in stage 23 chick eye by in situ hybridization: Bright-field and respective dark-field parasagittal sections of the eye. Panels are arranged from medial (top) to lateral (bottom). The orientation of all the sections is indicated in $A$ : nasal (anterior) $(N)$, temporal (posterior) $(T)$, dorsal $(D)$, and ventral (V). Retina $(r)$, pigmented epithelium $(p e)$, and lens $(l)$ are indicated. Arrow marks position of the ventral furrow. Scale bar, $100 \mu \mathrm{m}$. 
Figure 5. Expression pattern of SOHo- $I$ in posthatch day $0(\mathrm{P} 0)$ chick retina and stage 23 optic stalk by in situ hybridization. Outer nuclear layer (onl), inner nuclear layer $(\mathrm{inl})$, ganglion cell layer $(\mathrm{gcl})$, and optic stalk (os) are indicated. $A$, Bright-field photograph of cross section through $\mathrm{P} 0$ chick retina; $B$, same section shown in dark field. $C$, Bright-field photograph of parasagittal section through the optic stalk; $D$, same section shown in dark field. $E$, Brightfield photograph of oblique parasagittal section through optic stalk; $F$, same section shown in dark field. Scale bar, 100 $\mu \mathrm{m}$.
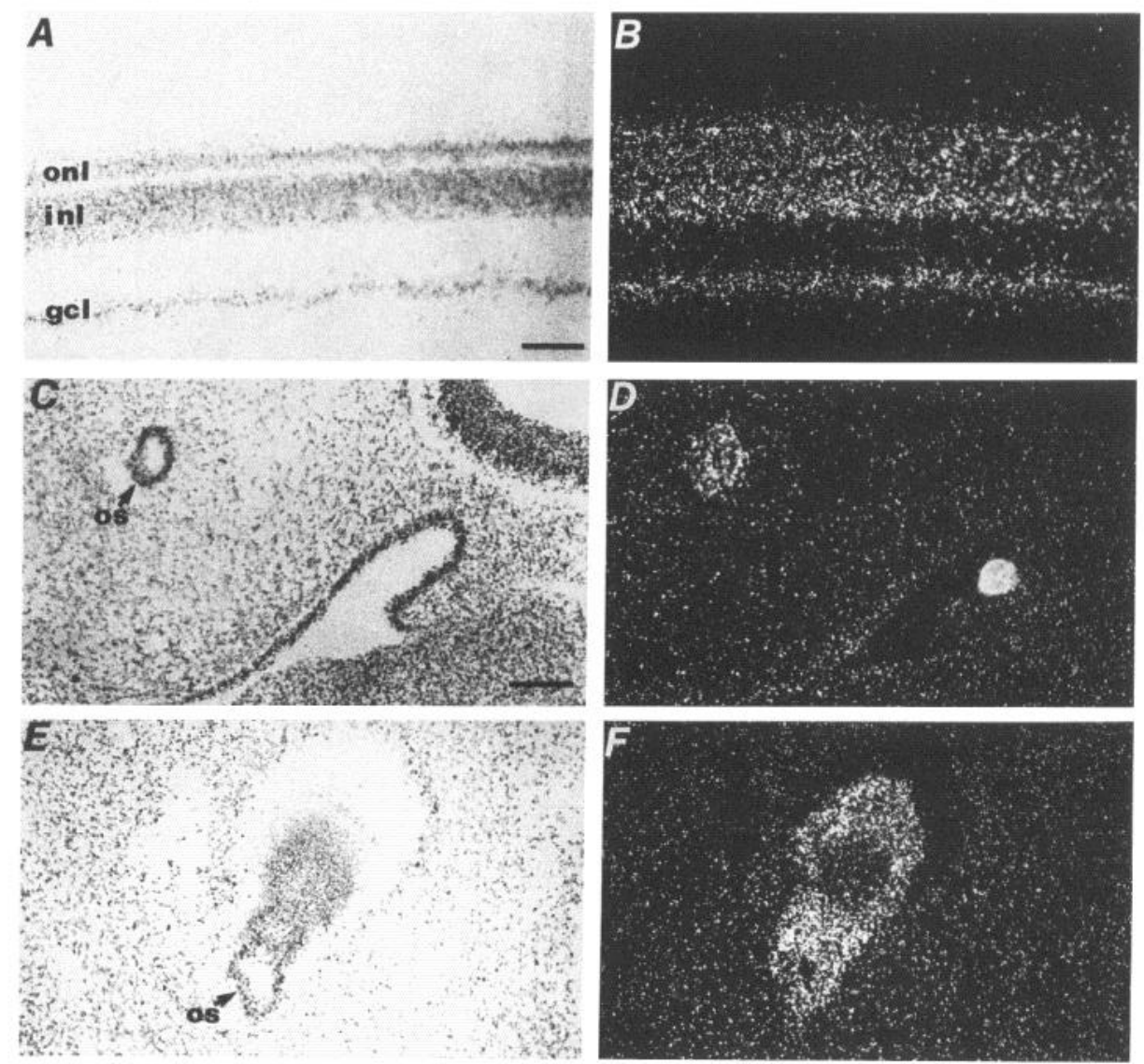

hearing and balance, and the associated neurons of the VIIIth cranial ganglion. In the chick, the otic pit is formed on E2. At this same time, neural progenitor cells bud off the ventromedial wall to form the VIIIth cranial ganglion. The otocyst is formed by E3 (stage 18). From E3 to E6.5 (stage 30), evagination and differential growth of the walls of the otocyst serve to subdivide the inner ear into all of its component parts (semicircular canals, utricle, saccule, basilar papilla, and lagena). Separation of the sensory organs into eight discrete components occurs gradually (Knowlton, 1967). What is initially a contiguous patch of cells on the anteroventromedial region of the otic pit on E2.5 has subdivided into three main sensory regions by E4 (stage 24): (1) an anteroventral area that gives rise to the sensory organs of the utricle and the anterior and lateral semicircular canals, (2) a posteroventrolateral region that gives rise to the sensory organs of the posterior semicircular canal and the macula neglecta, and (3) a ventromedial area that gives rise to the sensory organs of the saccule and the enlarging primitive lagena. The primitive lagena further separates into two regions: the definitive lagena (a vestibular organ) and the basilar papilla (the auditory organ). The final pattern of eight discrete sensory organs is apparent by E6.5 (stage 30). The majority of the hair cells and supporting cells in the basilar papilla undergo their final mitotic division between E5 and E8 (Katayama and Corwin, 1989). The generation of the vestibular hair cells probably precedes that of the auditory hair cells by approximately $1-1.5 \mathrm{~d}$, based on the initial expression of a hair cell marker (Bartolami et al., 1991) and comparisons with cell generation in the mouse inner ear (Ruben, 1967).
The expression of $\mathrm{SOHo}-\mathrm{I}$ was studied at three time points during the course of sensory organogenesis: E2, E4 (stage 23), and E4.5 (stage 26). On E2 the otic pit showed an asymmetric distribution of $\mathrm{SOHo}-1$, with the most intense staining in the posterolateral portion of the optic pit (Fig. 3).

At stage 23, high $\mathrm{SOHo}-1$ expression is still primarily a contiguous patch, with highest levels in the lateral third of the otic vesicle and continuing posteroventrally in the middle third of the otic vesicle (Fig. 6). A second region of high expression is found at the junction of the primordial endolymphatic duct in some sections (data not shown). The endolymphatic duct is a nonsensory structure that will eventually connect the inner ear fluid system to the brain ventricular system. Some cells in the adjacent VIIIth cranial ganglion are also expressing detectable amounts of $\mathrm{SOHo}-1$ (data not shown).

By stage 26, the spatial distribution of $\mathrm{SOHo}-\mathrm{I}$ in the otic epithelium has become more complex and patchy (Fig. 7). Threedimensional reconstruction of the expression pattern from serial sections was helpful in recognizing the significance of the patchy distribution (Fig. 8). $\mathrm{SOHo}-\mathrm{I}$ appears to be high in regions that will not form sensory organs. That is, expression is absent in an anteroventral patch, a posteroventrolateral patch, and two separate patches on the ventromedial surface that may represent the forming sensory organs in the saccule and lagena (Fig. 8). By stage 26, $\mathrm{SOHo}-\mathrm{I}$ is also uniformly high on the primordial endolymphatic duct. Expression is still evident in the Vth and VIIIth cranial ganglion (Fig. $7 B, D$ ), although the intensity of hybridization in the VIIIth cranial ganglion appears to vary in different regions, and is not particularly high in Figure 7. 

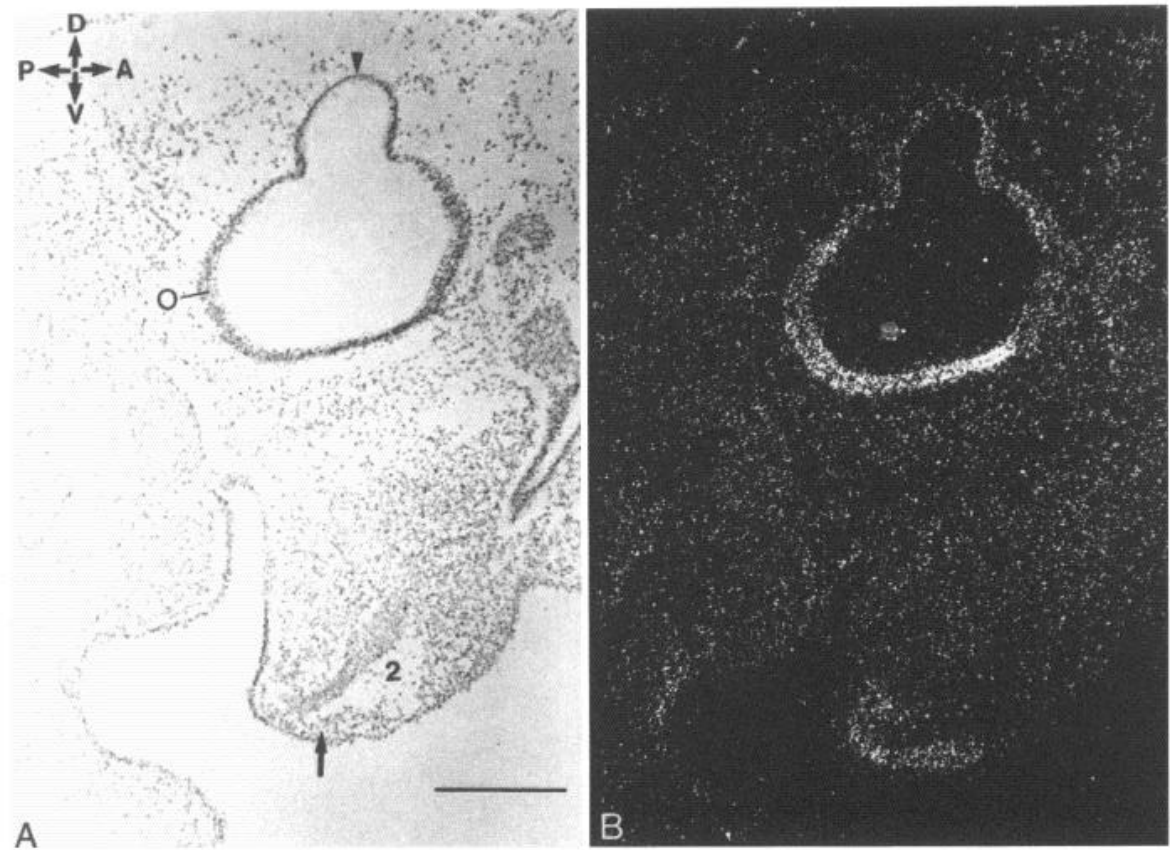

Figure 6. Expression pattern of SOHo- 1 in otocyst and hyoid arch at stage 23 by in situ hybridization: parasagittal section (labeled as follows: otocyst, $o$; endolymphatic duct, arrowhead; and second branchial arch, 2. Anterior $(A)$, posterior $(P)$, dorsal $(D)$, and ventral $(V)$ are as indicated. $A$, Brightfield photograph of stage 23 embryo through otocyst and second branchial arch (lateral portion); $B$, same section shown in dark field. Scale bar, $100 \mu \mathrm{m}$.

\section{SOHo-1 expression in the second branchial arch and frontonasal process}

At stage 23, in situ hybridization revealed that the apical tip of the second branchial (or hyoid) arch expressed high levels of SOHo- 1 transcript in mesenchymal cells (Fig. $6 \mathrm{~B}$ ). By stage 26 , $\mathrm{SOHo}-\mathrm{I}$ expression has expanded to encompass the entire second arch (Fig. $7 F$ ) except the gap in the middle, which may correspond to the superior cervical sinus. Most of the mesenchymal cells of the second arch are neural crest derived, having migrated from the fourth rhombomere (Lumsden et al., 1991). The hyoid arch in chick gives rise to portions of the columella auris, the middle ear bone of chicks, and part of the hypobranchial skeleton, which supports the tongue (Romanoff, 1960). At stage 23, a small but intense domain of expression was observed in the mesenchyme of a restricted portion of the frontonasal process (data not shown). This region will ultimately generate tissue of the forehead and dorsal beak.

\section{SOHo-1 expression in the DRG}

The DRG, which at stage 26 are visible as periodic condensations of cells along the length of the spinal cord, clearly hybridized to the antisense probe of $\mathrm{SOHO}^{-1}$ (Fig. 9B). DRG along the entire length of the spinal cord expressed the $\mathrm{SOHo}-1$ gene at apparently equal levels. Unlike the earlier pattern at stage 14.5 in which $\mathrm{SOHo}-1$ was restricted to the anterior portion of the embryo, the pattern in the DRG extended to the caudal portions of the spinal cord.

\section{Discussion}

We have cloned a novel homeobox gene and characterized its complex distribution in the embryonic chick nervous system during the early stages of neurogenesis. Its lack of homology to other identified mammalian and Drosophila homeobox genes and its striking homology to the sea urchin gene TgHbox 5 and the $C$. elegans gene ceh- 9 suggest that these genes represent a new class of homeobox genes. It is likely that homologs of SOHo- 1 will be identified in other organisms. While SOHo- 1 expression is mainly expressed in the developing nervous system, the expression patterns and functions of ceh-9 and $\mathrm{Tg}$ Hbox 5 have not been determined.

\section{Expression of SOHo-1 in the brain anlage}

Early expression of $\mathrm{SOHo}-1$ in the anterior CNS can be found throughout the brain anlage. The brain of stage 14.5 chick consists of the prosencephalon, the mesencephalon, and the rhombencephalon: three swellings at the anterior end of the neural tube. The timing of early $\mathrm{SOHo}-1$ expression in the chick brain approximately coincides with the expression of Emx-1 and Emx2, the mouse homologs of the Drosophila homeobox gene empty spiracles, and Otx1 and Otx2 (Simeone et al., 1992a,b), the mouse homologs of the Drosophila homeobox gene orthodenticle. Like these genes, $\mathrm{SOHo}-1$ has a clearly defined posterior expression boundary in the early neural tube. $\mathrm{SOHO}-\mathrm{I}$ extends farther caudally than $O t x$ and Emx genes, overlapping in the hindbrain with members of the Hox-2 cluster. The mouse homologs of the gene Distal-less, Dlx (Price et al., 1991) and TES-I (Porteus et al., 1991), are also present in the developing anterior portions of the brain at slightly later embryonic times. Since SOHo- 1 expression includes the entire brain anlage by stage 14.5, it could act in conjunction with chick homologs of Emx1, Emx-2, Dlx, Otx1, Otx2, and TES-1 in specifying portions of the anterior neural tube and with the Hox class of homeobox genes in specifying portions of the hindbrain. At later developmental times (E4), $\mathrm{SOHo}-\mathrm{I}$ expression was seen at above background levels in cells lining the brain ventricles, but the level was not comparable to that seen in retina, otocyst, or DRG (data not shown).

\section{Expression of $\mathrm{SOHo}-1$ in the eye}

The vertebrate eye forms from an evagination of the neural tube, the optic vesicle. Shortly thereafter, at stage 13, the optic vesicle invaginates to form the optic cup. The optic cup is composed of an inner layer that will give rise to retina and an outer layer that will form the pigmented epithelium, a non-neuronal supporting tissue. $\mathrm{SOHO}-\mathrm{l}$ is expressed in what appears to be 

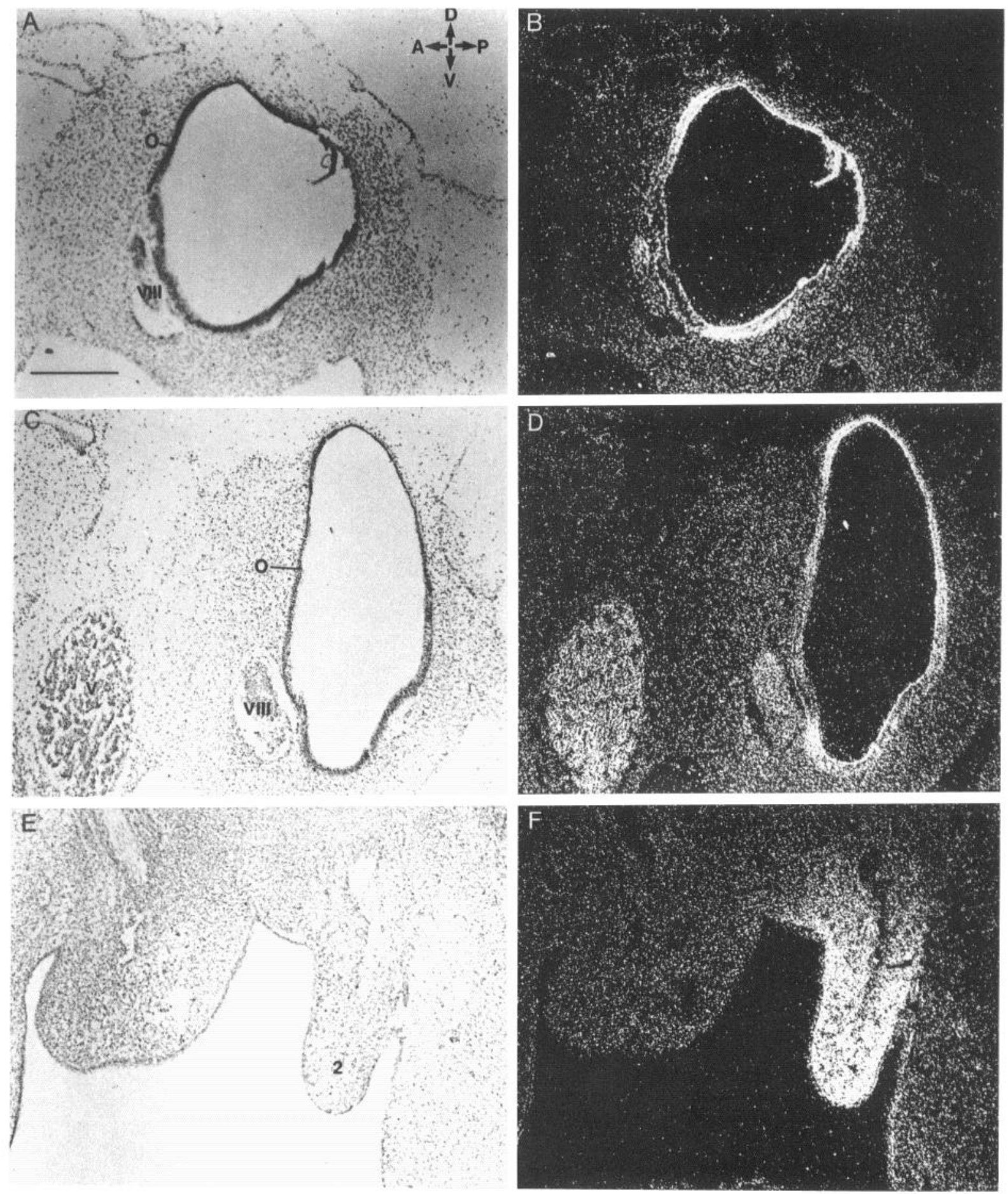

Figure 7. Expression pattern of SOHo- 1 in otocyst and hyoid arch at stage 26 by in situ hybridization. The A-P orientation of these sections are reversed relative to sections in Figure 6. All sections are parasagittal, and relevant embryonic structures are labeled as follows: ootocyst, $o$; Vth cranial ganglion, $V$; VIIIth cranial ganglion, VIII; and second branchial arch, 2. Anterior $(A)$, posterior $(P)$, dorsal $(D)$, and ventral $(V)$ are as indicated. $A$, Bright-field photograph of stage 26 embryo through otocyst (lateral portion); $B$, same section shown in dark field. $C$, Bright-field photograph of stage 26 embryo through otocyst but more medial than $A$ and $B ; D$, same section shown in dark field; $E$, Bright-field photograph of stage 26 embryo through hyoid arch; $F$, same section shown in dark field. Scale bar, $100 \mu \mathrm{m}$.

the retinal anlage (inner layer) and perhaps the outer layer as well. By stage 23 ( $\sim$ E3.5), when most of the retinal cell types are being generated, the lens is well developed, and the tissue giving rise to the pigmented epithelium is starting to become pigmented, the asymmetric expression of $\mathrm{SOHO}-\mathrm{I}$ along the A-P axis of the retina is striking. Anterior (nasal)-posterior (tem- poral) asymmetry in the retina, as reflected in ganglion cell targeting, does not become apparent until much later, after axons emerge from the retina and segregate according to their A-P position in the retina at approximately E6. While some retinal ablations suggested that this axis is fixed in the chick between E3 and E4 (de Long and Coulombre, 1965), other ablation stud- 


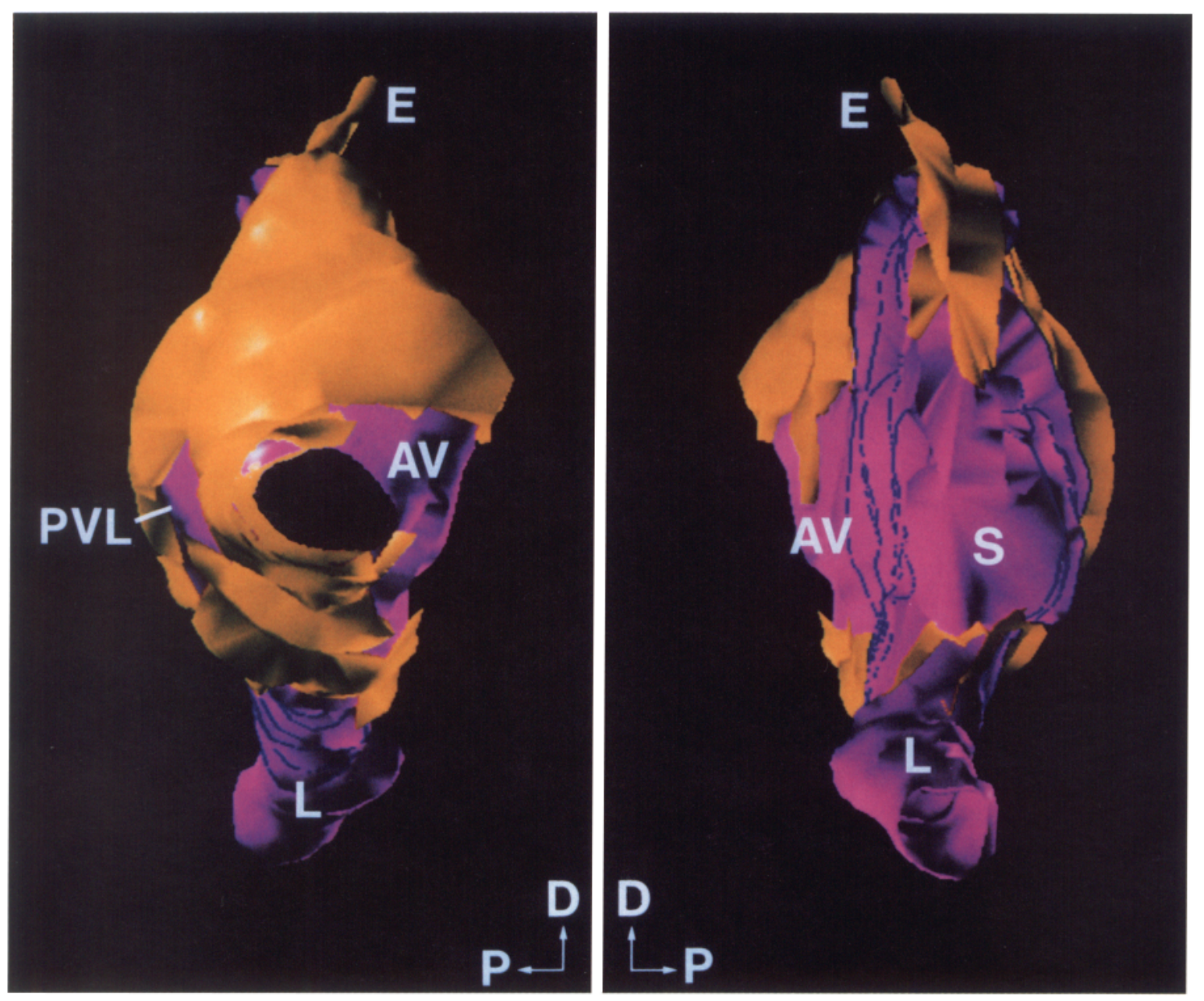

Figure 8. Three-dimensional reconstruction of expression pattern of $\mathrm{SOHo}-1$ in otocyst at stage 26. The otocyst is shown from both a lateral (left) and a medial (right) view. Positive expression domains are indicated in yellow and negative expression domains are indicated in pink. Developing sensory patches are negative, including an anteroventral patch $(A V)$, a posteroventral patch $(P V L)$, the saccular macula $(S)$, and the primitive lagena $(L)$. The endolymphatic duct $(E)$ is positive, as are the developing semicircular canals. Orientation is as shown: dorsal, $D$; posterior, $P$. A series of medial sections were used as sense controls; these are indicated as blue broken lines, since their $\mathrm{SOHo-1}$ expression levels cannot be assessed for this specimen.

ies indicated that this occurs between stages 12 and $13(\sim \mathrm{E} 2)$ (Crossland et al., 1974). Early determination of the A-P axis of the chick retina is consistent with experiments in Xenopus in which small groups of undifferentiated retinal cells were labeled and transplanted to other locations in the retina. The descendent retinal ganglion cells acted as though they retained their original positional value in that the axons grew to the original tectal target area (Fraser, 1991).

Recently, two studies employed monoclonal antibodies to label proteins that were preferentially distributed in the temporal (posterior) retina in chick (Trisler, 1990; McLoon, 1991). One of the monoclonal antibodies recognized the cell surface protein $\mathrm{TOP}_{\mathrm{AP}}$, which was preferentially localized in the posterior retina in a graded fashion throughout most of embryonic development (E4-E18) (Trisler, 1990). A reciprocal pattern was seen in the chick tectum, suggesting that $\mathrm{TOP}_{\mathrm{AP}}$ may play a role in axonal targeting. The other cell surface protein, temporal retina axon protein (TRAP) (McLoon, 1991), was first detected at the end of E3, on a small patch of ganglion cell axons dorsal to the optic stalk, but its distribution was not asymmetric with respect to the A-P (nasal-temporal) axis. By E6, the differentiating posterior ganglion cell axons stained heavily while the anterior axons stained poorly; the spatial expression between E3 and E6 was not described. The presence of TRAP on developing ganglion cell axons, and the absence of TRAP on progenitor cells, where patterning may take place (Fraser, 1991), may suggest that it plays a role in axon guidance. The earlier expression of $\mathrm{SOHo-1}$ at E2 and its homology to homeobox genes may suggest that it plays an important role in either specifying or reflecting the A-P patterning of the retina. However, due to limitations of the whole-mount in situ protocol, the first appearance of the asymmetric distribution of $\mathrm{SOHo}-\mathrm{l}$ has not yet been established. If $\mathrm{SOHo}-\mathrm{I}$ is involved in A-P patterning of the retina, then the patch of expression that crosses the ventral furrow may indicate that the developmentally defined anterior compartment of the retina may not directly correspond to the anatomical one defined by the furrow.

Several molecules have been shown to have an asymmetric or graded distribution in the retinal D-V and A-P axes (Trisler et al., 1981; Constantine-Paton et al., 1986; Trisler and Collins, 1987; Nornes et al., 1990; Trisler, 1990; McCafferty et al., 1991; McLoon, 1991; Monaghan et al., 1991). Of particular interest, with respect to establishing the retinal D-V axis, are Pax2 and aldehyde dehydrogenase (AHD-2). Message for Pax2, a homeo- 

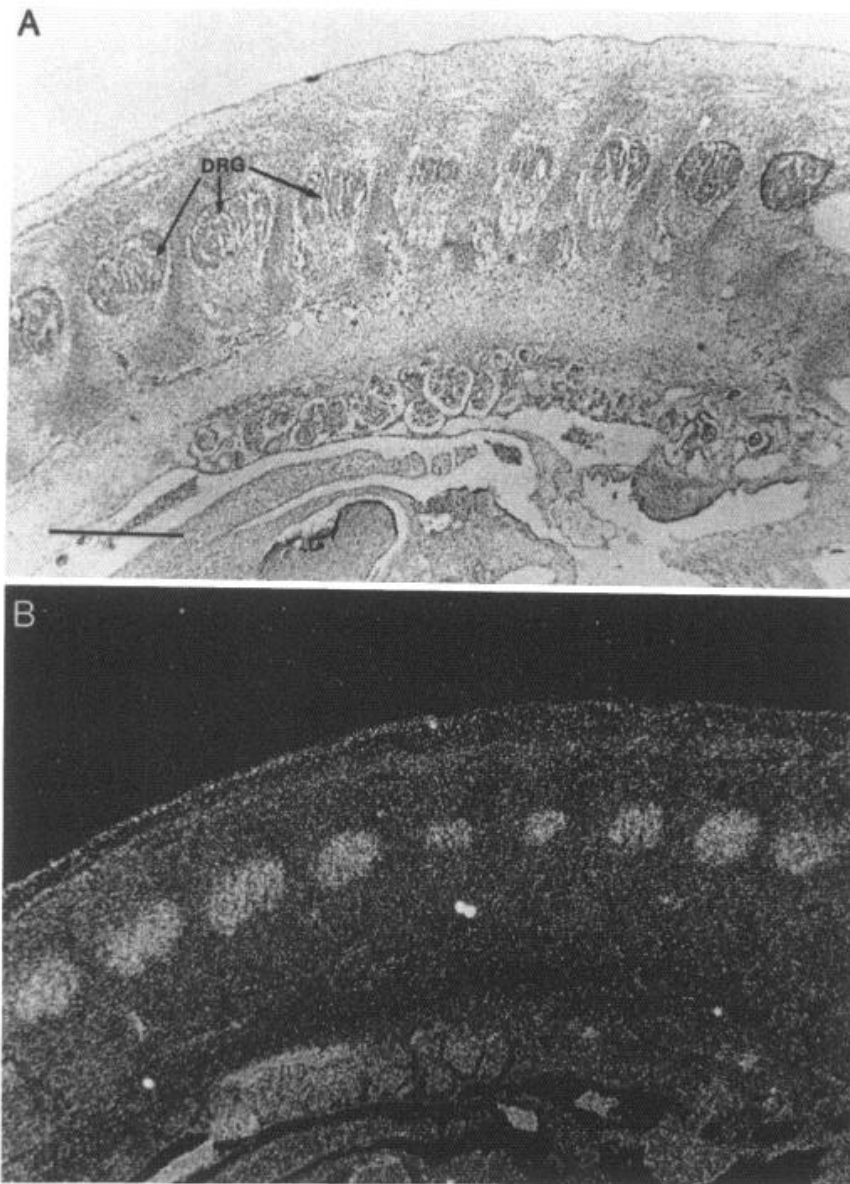

Figure 9. Expression pattern of $\mathrm{SOHo}-1$ in dorsal root ganglion (DRG) by in situ hybridization: medial parasagittal section through stage 26 embryo to reveal $\mathrm{SOHo}-1$ expression in the DRG. $A$, Bright-field photograph of stage 26 embryo through the DRG; $B$, same section shown in dark field. Scale bar, $100 \mu \mathrm{m}$.

domain gene with a paired box, is preferentially expressed in the ventral retina (Nornes et al., 1990). AHD-2, an enzyme capable of producing retinoic acid from retinaldehyde, is expressed in the dorsal retina (McCafferty et al., 1991), although recent evidence indicates that ventral retina can synthesize more retinoic acid than dorsal retina (McCafferty et al., 1992). Pax2, AHD-2, TRAP, and $\mathrm{SOHo}-1$ are all asymmetrically distributed in the retina; each molecule is distributed with more on one half of the retina than on the other half. The distribution of these molecules suggests that the retina may be organized in compartments of nasal, temporal, dorsal, and ventral. Compartment-based molecules, in conjunction with as yet undetermined gradient molecules, may specify retinal position, enabling precise topographical connections to be formed.

\section{Expression of $\mathrm{SOHo}-1$ in the ear}

By stage 14.5, the otic placode has invaginated to form the otic pit but has not yet completed closure to form the otic vesicle. At this stage, the expression of $\mathrm{SOHO}-1$ delineated the nonneurogenic region of the otic pit on the lateral posterior half. The negative regions are fated to become sensory end organs as well as neurons of the VIIIth cranial ganglion (Knowlton, 1967; D'Amico and Noden, 1983). This would suggest that the $\mathrm{SOHO}-1$ expression seen later in the VIIIth cranial ganglion, by stage 23 , reflects transcriptional activation after the cells have migrated from the otic pit and associated to form a ganglion.

Recently, three homeobox genes (dlx 3, msh- $D$, and $m s h-C)$ were found to be expressed in a spatially restricted pattern in the developing zebrafish ear (Ekker et al., 1992). The $d l x 3$ gene is first expressed in a group of ectodermal cells prior to their organization into the otic placode. We have not examined whether $\mathrm{SOHo}-1$ is expressed at an equivalent stage in the chick. Later in zebrafish development, at $16 \mathrm{hr}$, approximately the equivalent of stage 14.5 in the chick, the $d l x-3$ gene is expressed in the dorsal posterior region of the otic placode in what would be an adjacent and nonoverlapping region of the otic placode with respect to $S O H o-1$ expression. By $24 \mathrm{hr}, d l x-3$ is expressed in the dorsomedial portion of the otocyst and $m s h-D$ was expressed dorsally in a portion of the otocyst that is central with respect to the lateral medial axis. If, as suggested by Ekker et al. (1992), $d l \times 3$ and $m s h-D$ expression are affected by inductive signals such as int-2 (Repressa et al., 1991), then the adjacent and nonoverlapping domain of $\mathrm{SOHO}-\mathrm{I}$ expression may restrict which areas of the otocyst are capable of responding to these signals. Alternatively, the domain of $\mathrm{SOHo}-1$ expression may reflect its location relative to the hindbrain or some other structure. For example, since the $\mathrm{SOHo-I}$ domain is most distant from the hindbrain, its expression may be selectively downregulated by a hypothetical signal originating from the hindbrain, thereby explaining the spatial pattern of expression in the otocyst. Such a model should be testable by experimental manipulation. Later, $m s h-D$ and $m s h-C$ are expressed in macular precursor cells that give rise to the hair cells. These cells do not express $\mathrm{SOHO}-\mathrm{I}$ in the chick.

\section{SOHo-1 expression in the DRG}

The expression of $\mathrm{SOHo}-1$ in the developing DRG was apparent by stage 23 and strongly positive at stage 26 . The neural crest cells that give rise to the DRG migrate from the neural tube and first appear as recognizable ganglionic masses on both sides of the spinal cord between stages 18 and 19. Neuroblasts and differentiated bipolar neurons with large cell bodies commingle in the DRG until E8-E10, when differentiated and undifferentiated cells segregate into the ventrolateral and dorsomedial regions of the DRG, respectively. Between E5 and E8 neuroblasts differentiate and send processes to the spinal cord and the dermis (Levi-Montalcini and Levi, 1943). While relatively high expression is seen in the mixed population of neuroblasts and differentiated neurons in the DRG at stage 26 (E4.5), detectable but low expression was seen by Northern analysis at E7. It is therefore possible that $\mathrm{SOHo}-1$ expression is extinguished as neuroblasts differentiate into mature neurons.

\section{SOHo-1 expression in the second branchial arch and cranial ganglia}

The second branchial (hyoid) arch expresses high levels of SOHo- 1 by stage 26 , as do the Vth and VIIIth cranial ganglia. The hyoid arch is mainly derived from neural crest cells of rhombomere 4 (Guthrie and Lumsden, 1991). Neurons of the Vth cranial ganglia are derived both from ectodermal placode and from the neural crest of rhombomere 2, while the neurons of the VIIIth cranial ganglia are derived from the otic placode. The expression of several Hoxb genes has also been found in the developing branchial arches and cranial ganglia in mouse. $H o x b-2$ and Hoxb-1 are both expressed in branchial arch 2 and in the VIIIth cranial ganglion (Frohman et al., 1990; Hunt et 
al., 1991), which roughly correlates with their anterior boundaries of expression. It has been suggested that neural crest cells already possess positional information prior to their migration to form cranial ganglia and branchial arches in the form of a combinatorial code of Hox genes (Hunt and Krumlauf, 1991). Classical transplantation experiments support this view; transplants of presumptive branchial arch 1 neural crest cells into the region of presumptive branchial arch 2 neural crest result in duplication of branchial arch 1 structures (Noden, 1983). Although $\mathrm{SOHO}-1$ was expressed in the rhombomeres, we find no evidence that the neural crest cells from this region express SOHO- 1 during migration to form the cranial ganglia and the branchial arch 2 . Since $\mathrm{SOHO}_{-1} 1$ is the first member of this class of homeobox genes to be found in vertebrates, the combinatorial models proposed for Hox cluster genes may not apply to its expression pattern. In fact, $\mathrm{SOHO}-1$ appears to be downstream of the Hoxb genes in its temporal pattern of expression. Unlike $H o x b-1$ that is expressed in the migrating neural crest, which will form the sccond branchial arch, $\mathrm{SOHO}^{-} \mathrm{l}$ is expressed $2 \mathrm{~d}$ after the neural crest cells arrive at the second branchial arch. The initial expression of $\mathrm{SOHo}-1$ in the extreme ventral portion of the second branchial arch at stage 23 followed by an expansion of expression to fill the whole arch by stage 26 suggests that the underlying mesoderm may be receiving a signal from the apical ectodermal tip of the hyoid arch.

\section{Summary}

SOHO- 1 has a complex pattern of expression in the develoning chick nervous system. It is coexpressed with a number of other homeobox genes ( $E m \times 1, E m \times 2, T E S-1, D l x, O t \times 1$, and Otx2) and Hox cluster members, which by analogy to Drosophila are involved in the patterning of the nervous system. However, like some of the Drosophila homeobox genes (i.e., en, eve, ftz), which function differently in different tissues at different developmental times (Doe et al., 1987, 1988; DiNardo et al., 1988), SOHO-1 may also have several functions depending on the combination of other factors present. In the retina, its A-P asymmetry would suggest that it is involved in specifying or reflecting positional information, while in the otocyst it appears to be restricted to non-neurogenic areas. In the DRG, and possibly in the $V$ th and VIIIth cranial ganglia, it may be required for their condensation, but not their subsequent differentiation, whilc in the brain anlage it may act in concert with other homeobox genes that may have the job of defining smaller portions of the brain. It is also possible that $S O H O-I$ could be involved in the singular function of conveying positional information to the neurons of the retina, DRG, and cranial ganglia, instructing them where to send their axons.

\section{References}

Akam M (1987) The molecular basis for metameric pattern in the Drosophila embryo. Development 101:1-22.

Awgulewitsch A. Jacobs D (1992) Deformed autoregulatory element form Drosophila functions in a conserved manner in transgenic mice. Nature 358:341-344.

Bartolami S, Goodyear T, Richardson G (1991) Appearance and distribution of the $275 \mathrm{kD}$ hair-cell antigen during development of the avian inner ear. J Comp Neurol 314:777-788

Chirgwin JM, Przbyla AE, MacDonald RJ, Rutter WJ (1979) Isolation of biologically active ribonucleic acid from sources enriched in ribonucleases. Biochemistry 18:5294-5299.

Chisaka O, Musci TS, Capecchi MR (1992) Developmental defects of the ear, cranial nerves and hindbrain resulting from targeted disruption of the mouse homeobox gene Hox-1.6. Nature 355:516-520.
Chomczynski P, Sacchi N (1987) Single-step method of RNA isolation by acid guanidinium thiocyanate-phenol-chloroform extraction. Anal Biochem 162:156-159.

Cohen SM, Jürgens G (1990) Mediation of Drosophila head development by gap-like segmentation genes. Nature 346:482-485.

Conlan RA, Rossant J (1992) Exogenous retinoic acid rapidly induces anterior ectopic expression of murine Hox-2 genes in vivo. Development 116:357-368.

Constantine-Paton M, Blum AS, Mendez-Otero R, Barnstable CJ (1986) A cell surface molecule distributed in a dorsoventral gradient in the perinatal rat retina. Nature 324:459-462.

Crossland W, Cowan W, Rogers L, Kelly J (1974) The specification of the retino-tectal projection in the chick. J Comp Neurol 155:127164

D'Amico-Martel A, Noden DM (1983) Contributions of placodal and neural crest cells to avian cranial peripheral ganglia. Am J Anat 166: $445-468$.

de Long GR, Coulombre AJ (1965) Development of the retinotectal topographic projection in the chick embryo. Exp Neurol 13:351-363.

DiNardo S, Sher E, Heemskerk-Iongens I, Kassis JA, O'Farrell PH (1988) Two-tiered regulation of spatially patterned engrailed gene expression during Drosophila embryogenesis. Nature 332:604-609.

Doe CQ, Hiromi Y, Gehring WJ, Goodman CS (1987) Expression and function of the segmentation gene fushi tarazu during Drosophila neurogenesis. Science 239:170-175.

Doe CQ, Smouse D, Goodman CS (1988) Control of neuronal fate by the Drosophila segmentation gene evenskipped. Nature 333:376378.

Ekker M, Akimenkok M-A, Bremiller R, Westerfield M (1992) Regional expression of three homeobox transcripts in the inner ear of zebrafish embryos. Neuron 9:27-35.

Falzon M, Sanderson N, Chung SY (1987) Cloning and expression of rat homeo-box-containing sequences. Gene 54:23-32.

Finkelstein R, Perrimon N (1990) The orthodenticle gene is regulated by bicoid and torso and specifies Drosophila head development. Nature 346:485-488.

Fraser SE (1991) Relative roles of positional cues and activity-based cues in the patterning of the retinotectal projection. In: Development of the visual system (Lam D, Shatz C, eds) pp 123-132. Cambridge: MIT Press.

Frohman MA, Boyle M, Martin GR (1990) Isolation of the mouse Hox-2.9 gene; analysis of embryonic expression suggests that positional information along the anterior posterior axis is specified by mesoderm. Development 110:589-607.

Gubler U (1988) A one tube reaction for the synthesis of blunt-ended double-stranded cDNA. Nucleic Acids Res 16:2726.

Guthrie S, Lumsden A (1991) Formation and regeneration of rhombomere boundaries in the developing chick hindbrain. Development 112:221-229.

Hamburger V, Hamilton $H$ (1951) A series of normal stages in the development of the chick embryo. J Morphol 88:49-92.

Harris WA (1989) Local positional cues in the neuroepithelium guide retinal axons in embryonic Xenopus brain. Nature 339:218-221.

Hawkins NC, McGhee JD (1990) Homeobox containing genes in the nematode Caenorhabditis elegans. Nucleic Acids Res 18:6101-6106.

Hunt P, Krumlauf R (1991) Deciphering the Hox code: clues to patterning branchial regions of the head. Cell 66:1075-1078.

Hunt P, Wilkinson D, Krumlauf R (1991) Patterning the vertebrate head: murine Hox 2 genes mark distinct subpopulations of premigratory and migrating cranial neural crest. Development 112:43-50.

Joyner AL, Kornberg T, Coleman KG, Cox DR, Martin GR (1985) Expression during embryogenesis of a mouse gene with sequence homology to the Drosophila engrailed gene. Cell 43:29-37.

Katayama A, Corwin JT (1989) Cell production in the chicken cochlea. J Comp Neurol 281:129-135.

Kessel M, Schulze F, Fibi M, Gruss P (1987) Primary structure and nuclear localization of a murine homeodomain protein. Proc Natl Acad Sci USA 84:5306-5310.

Kingston R (1989) In: Current protocols in molecular biology, Vol 2 (Ausubel FM, Brent R, Kingston RE, Moore DD, Seidman JG, Smith JA, Struhl K, eds). New York: Wiley.

Knowlton VY (1967) Correlation of the development of membranous and bony labyrinths, acoustic ganglia, nerves, and brain centers of the chick embryo. J Morphol 121:179-208.

Kozak M (1986) Point mutations define a sequence flanking the AUG 
initiator codon that modulates translation by eukaryotic ribosomes. Cell 44:283-292.

Lazzaro D, Price M, De Felice M, Di Lauro R (1991) The transcription factor $T T F-1$ is expressed at the onset of thyroid and lung morphogenesis and in restricted regions of the foetal brain. Development 113: 1093-1104.

Levi-Montalcini R, Levi G (1943) Recherches quantatives sur la marche du processus de differenciation des neurones dans les ganglions spinaux de l'embryon de poulet. Arch Biol (Liege) 54:183-206.

Lufkin T, Dierich A, LeMeur M, Mark M, Chambon P (1991) Disruption of the Hox-1.6 homeobox gene results in defects in a region corresponding to its rostral domain of expression. Cell 66:1105-1119.

Lumsden A, Sprawson N, Graham A (1991) Segmental origin and migration of neural crest cells in the hindbrain region of the chick embryo. Development 113:1281-1291.

Malicki J, Cianetti LC, Peschle C, McGinnis W (1992) A human Hox $4 B$ regulatory element provides head-specific expression in Drosophila embryos. Nature 358:345-347.

McCafferty P, Tempst P, Lara G, Dräger UC (1991) Aldehyde dehydrogenase is a positional marker in the retina. Development 112: 693-702.

McCafferty P, Lee M-O, Wagner MA, Sladek NE, Dräger UC (1992) Asymmetrical retinoic acid synthesis in the dorsoventral axis of the retina. Development 115:371-382.

McGinnis N, Kuziora MA, McGinnis W (1990) Human Hox-4.2 and Drosophila Deformed encode similar regulatory specificities in Drosophila embryos and larvae. Cell 63:969-976.

McLoon SC (1991) A monoclonal antibody that distinguishes between temporal and nasal retinal axons. J Neurosci 11:1470-1477.

Monaghan AP, Davidson DR, Sime CA, Graham E, Baldock R, Bhattacharya SS, Hill RE (1991) The $m s h$-like homeobox define domains in vertebrate eye. Development 112:1053-1061.

Morgan BA, Izpisua-Belmonte J-C, Deboule D, Tabin C (1992) Targeted expression of $\mathrm{Hox}-4.6$ in the avian limb bud causes apparent homeotic transformations. Nature 358:236-239.

Noden DM (1983) The role of the neural crest in patterning of avian cranial skclctal, connective, and muscle tissues. Dev Biol 96:144165.

Nornes HO, Dressler GR, Knapik EW, Deutsch U, Gruss P (1990) Spatially and temporally restricted expression of $\mathrm{Pax} 2$ during murine neurogenesis. Development 109:797-809.

Porteus MH, Bulfone A, Ciaranello RD, Rubenstein JLR (1991) Isolation and characterization of a novel cDNA clone encoding a homeodomain that is developmentally regulated in the ventral forebrain. Neuron 7:221-229.

Price M, Lemaistre M, Pischetolu M, Di Lauro R, Duboule D (1991) A mouse gene related to Distal-less shows a restricted expression in the developing forebrain. Nature 351:748-751.

Price M, Lazzaro D, Pohl T, Mattei M-G, Ruther U, Olivo J-C, Duboule D, Di Lauro R (1992) Regional expression of the homeobox gene $N k \times 2.2$ in the developing mammalian forebrain. Neuron 8:241-255.
Rentrop M, Knapp B, Winter H, Schweiser J (1986) Aminoalkylsilanetreated glass slides as support for in situ hybridization of keratin cDNAs to frozen tissue sections under varying fixation and pretreatment conditions. Histochem J 18:271-276.

Repressa J, Leon Y, Miner C, Giraldez F (1991) The int-2 protooncogene is responsible for induction of the inner ear. Nature 353: $561-563$.

Romanoff AL (1960) The avian embryo, pp 283-345, 365-381. New York: Macmillan.

Ruben RJ (1967) Development of the inner ear of the mouse: a radioautographic study of terminal mitoses. Acta Otolaryngol [Suppl] (Stockh) 220: 1-44

Simeone A, Mavilio F, Acampora D, Giampaolo A, Faiella A, Zappavigna V, D’Esposito M, Pannese M, Russo G, Boncinelli E, Peschle $C$ (1987) Two human homeobox genes, $\mathrm{cl}$ and $\mathrm{c} 8$ : structure analysis and expression in embryonic development. Proc Natl Acad Sci USA 84:4914-4918.

Simeone A, Acampora D, Gulisano M, Stornaiuolo A, Boncinelli E (1992a) Nested expression domains of four homeobox genes in developing rostral brain. Nature 358:687-690.

Simeone A, Gulisano M, Acampora D, Stornaiuolo A, Rambaldi M, Boncinelli E (1992b) Two vertebrate homeobox genes related to the Drosophila empty spiracles gene are expressed in the embryonic cerebral cortex. EMBO J 11:2541-2550.

Sperry RW (1963) Chemoaffinity in the orderly growth of nerve fiber patterns and connections. Proc Natl Acad Sci USA 50:703-710.

Tomlinson A, Kimmel B, Rubin GM (1988) rough. a Drosophila homeobox gene required in photoreceptors $\mathrm{R} 2$ and $\mathrm{R} 5$ for inductive interactions in the developing eye. Cell 55:771-784.

Trisler D (1990) Cell recognition and pattern formation in the developing nervous system. J Exp Biol 153:11-27.

Trisler D, Collins F (1987) Corresponding spatial gradients of TOP molecules in the developing retina and optic tectum. Science 237 1208-1209.

Trisler GD, Schneider MD, Nirenberg M (1981) A topographic gradient of molecules in retina can be used to identify neuron position. Proc Natl Acad Sci USA 78:2145-2149.

Vogelstein B, Gillespie D (1979) Preparative and analytical purification of DNA from agarose. Proc Natl Acad Sci USA 76:615-619.

Wang GVL, Dolecki GJ, Carlos R, Humphreys T (1990) Characterization and expression of two sea urchin homeobox gene sequences. Dev Genet 11:77-87.

Wright CVE, Cho KWY, Fritz A, Burglin TR, De Robertis EM (1987) A Xenopus laevis gene encodes both homeobox-containing and homeobox-less transcripts. EMBO J 6:4083-4094.

Zeller R, Rogers M (1991) In situ hybridization of riboprobes to RNA in tissue sections. In: Current protocols in molecular biology, Vol 2 (Ausubel FM, Brent R, Kingston RE, Moore DD, Seidman JG, Smith JA, Struhl K, eds), pp. X.1.1-X.6.3. New York: Wiley. 